\title{
O PAPEL DO CRM SOCIAL EM UMA INSTITUIÇÃO DE ENSINO: O CASO DO INSTITUTO FEDERAL DE EDUCAÇÃO, CIÊNCIA E TECNOLOGIA DO RIO GRANDE DO NORTE
}

\author{
M. V. D. ASSUNÇÃO ${ }^{1 *}$, R. L. S. SILVA ${ }^{1}$ e T. M. D'AMORE ${ }^{2}$ \\ ${ }^{1}$ Instituto Federal de Educação, Ciência e Tecnologia do Rio Grande do Norte - IFRN \\ ${ }^{2}$ Universidade Federal do Rio Grande do Norte - UFRN \\ marcus.assuncao@ifrn.edu.br*
}

Artigo submetido em março/2015 e aceito em julho/2015

DOI: $10.15628 /$ holos.2015.2888

\section{RESUMO}

O presente estudo objetiva compreender o papel do CRM Social, através das mídias sociais, no âmbito de uma instituição de ensino. A instituição escolhida para a pesquisa foi o Instituto Federal de Educação, Ciência e Tecnologia do Rio Grande do Norte através de seu Departamento de Comunicação Social e Imprensa. A pesquisa caracterizou-se como sendo Exploratória, com abordagem qualitativa, utilizando-se ainda da pesquisa bibliográfica seguida de análise de conteúdo para a discussão dos resultados. A coleta de dados foi realizada por meio de uma entrevista semiestruturada com duas servidoras do departamento de Comunicação da Instituição. Os resultados mostraram que o IFRN estabeleceu uma aproximação com a comunidade por meio das mídias sociais, no entanto, há ainda a necessidade de se melhorar a estrutura que suporta esse sistema informacional.

PALAVRAS-CHAVE: Instituição de ensino, Mídias sociais, CRM Social

\section{THE ROLE OF SOCIAL CRM IN AN EDUCATION INSTITUTE: THE FEDERAL INSTITUTE OF EDUCATION, SCIENCE AND TECHNOLOGY OF RIO GRAND DO NORTE CASE}

\author{
ABSTRACT \\ This study aims to understand the role of Social CRM \\ through social media as part of an educational \\ institution. The institution chosen for the research was \\ the Federal Institute of Education, Science and \\ Technology of Rio Grande do Norte, through its \\ Communication Department and Social Media. The \\ research was characterized as Exploratory, qualitative \\ approach, using even the literature followed by content
}

analysis to the discussion of results. Data collection was conducted through a structured interview with two employees of the Communications Department of the Institution. The results showed that the IFRN established closer ties with the community through social media, however, there is still a need to improve the structure that supports this information system.

KEYWORDS: Education institution, Social media, Social CRM. 


\section{INTRODUÇÃO}

Da última década em diante, o uso racional da informação tem sido bastante debatido, tanto pela academia quanto pelas organizações, dada a importância atribuída a um bom controle dos recursos informacionais e suas difusões. As organizações tiveram que passar por significativas transformações em suas estruturas e sistemas a fim de se adaptarem as novas necessidades impostas pelo mercado. $\mathrm{O}$ que antes poderia ser resolvido em algumas horas ou até minutos, hoje já se pode solucionar em segundos, a partir de uma simples ligação telefônica via celular, uma videoconferência ou através das redes sociais. Uma reunião, por exemplo, pode ser marcada através das mídias sociais sem que seja necessária ao menos uma ligação telefônica ou um e-mail.

As organizações passaram a trabalhar a informação cada vez mais de forma instantânea, possibilitando um fortalecimento no relacionamento com seus clientes através de sistemas de relacionamento com o cliente (CRM) multifacetados capazes de identificar suas necessidades de forma rápida e objetiva. As mídias sociais integram esses CRM's de forma a auxiliá-los nas difusões das informações em massa, onde a organização consiga atingir o maior número de clientes de forma imediata através das redes formadas pelos clientes.

Essas redes sociais buscam integrar e atualizar pessoas de forma a estarem sempre informadas, seja em casa, no trabalho ou no ambiente escolar, de tudo que acontece no mundo e com suas redes de interesse. É nessa perspectiva que as instituições de ensino enquanto organizações têm buscado interagirem com seus alunos no intuito de acelerarem a dissipação das informações a fim de manter sua rede atualizada e bem informada sobre as ações decorridas na instituição. Professores buscam manter esse canal com seus alunos, possibilitando uma extensão das atividades de sala de aula através das mídias e de forma imediata.

Com o intuito de melhor compreender o papel das mídias sociais no sistema de difusão da informação em um ambiente de ensino, optou-se por realizar o estudo no Instituto Federal de Educação, Ciência e Tecnologia do Rio Grande do Norte (IFRN) dada sua vasta e complexa estrutura educacional que é composta de 19 campi e uma reitoria, mais de 2.000 servidores e aproximando-se de 35.000 alunos. A instituição é centenária e reconhecida nacionalmente pela qualidade no seu ensino. Diante do contexto apresentado, o objetivo da pesquisa é compreender o papel do CRM Social no âmbito de uma instituição de ensino.

Este trabalho está dividido em cinco seções. Após esta breve introdução, na segunda seção é feita a revisão da literatura de CRMS e, é discutida a relação das redes sociais nas instituições de ensino. A terceira seção apresenta à metodologia e o modelo de análise, em seguida, a quarta seção, traz os resultados e a discussão do estudo. Por fim, são feitas as considerações finais e limitações do estudo.

\section{CRM SOCIAL}

Em um mundo globalizado no qual a concorrência vem acirrando os mercados, nunca foi tão importante entender as necessidades do consumidor. Se diante desse cenário conquistar clientes novos parece difícil, mantê-los é uma tarefa ainda mais árdua. Por isso, as empresas 
estão se aproximando cada vez mais dos consumidores e buscando ampliar seu grau de conhecimento sobre eles.

Atuando nessa fronte existe o CRM, ou Costumer Relationship Management (gestão do relacionamento com o cliente), que Kotler (2006, p.151) define como o "gerenciamento cuidadoso de informações detalhadas sobre cada cliente e de todos os pontos de contato com ele, a fim de maximizar sua fidelidade".

Payne; Frow (2005) explicam que o CRM une estratégias potenciais de relacionamento de marketing e tecnologia da informação com o objetivo de criar um lucrativo relacionamento de longo prazo com clientes e outros stakeholders importantes, fornecendo oportunidades aprimoradas para usar dados e informações para que ambos compreendam os clientes e criem valor para eles.

Nesse sentido, conforme os mesmos autores, o CRM teria o objetivo de:

- Atrair, fidelizar e satisfazer os clientes;

- Entender e antecipar as necessidades e anseios dos clientes;

- Superar suas expectativas e necessidades;

- Classificar os clientes;

- Aumentar a eficiência e eficácia da organização.

Porém, com o advento da internet e posteriormente com o surgimento das redes sociais, a relação entre empresa e cliente tornou-se mais dinâmica, rápida e delicada. Em questão de segundos uma reclamação no Twitter (www.twitter.com), Facebook (www.facebook.com) ou YouTube (www.youtube.com) - todas importantes redes sociais - sobre um produto com defeito ou um serviço mal feito pode correr o mundo e prejudicar seriamente a imagem de uma organização. Isso porque tais redes transmitem em efeito de cadeia uma grande quantidade de informações a todo momento e sem filtros, portanto qualquer um pode receber qualquer mensagem estando relacionada ou não ao autor da reclamação.

Para Verhoef; Lemon (2012), novos canais, tais como telefones móveis ou smartphones e novas mídias sociais, como sites de redes sociais criaram novos desafios e oportunidades para as organizações.

O SCRM - Social Costumer Relationship Management, ou gestão social do relacionamento com o cliente aparece focando justamente o relacionamento com os clientes das mídias sociais. Greenberg (2010) defende que o SCRM foi concebido para envolver o cliente em uma conversa colaborativa e fornecer um valor mutuamente benéfico em um ambiente de negócios confiável e transparente.

De acordo com Morgan; Chan; Lieberman (2010), a evolução do CRM para o SCRM trouxe as seguintes contribuições:

- Os processos passaram a ser definidos pelo consumidor ao invés de serem definidos pela empresa;

- Ao invés de horários comerciais, o consumidor busca se relacionar com a organização a qualquer hora;

- Ao invés de canais definidos de relacionamento com o cliente, o consumidor dispõe de 
vários canais dinâmicos;

- A relação entre consumidor e cliente deixou de ser transacional e se tornou interacional.

Isso possibilita ao consumidor buscar informações sobre um produto de interesse nas principais redes sociais, além de exigir respostas rápidas de uma empresa. Em contrapartida, Heidemann; Klier; Probst (2012); Holzner (2009) afirmam que com tais mídias as organizações podem analisar as tendências para futuras oportunidades de negócio bem como monitorar a reputação de seus produtos e serviços. Isso gera um inédito panorama de gestão, uma vez que as empresas estão enfrentando um novo desafio de como lidar com os seus clientes em todos os canais de tal forma que o valor do cliente seja criado e mantido (SCHONFELD, 2010).

Boa parte das redes sociais está atenta a essas tendências. Gorry (2011) relata que redes como Facebook ou Twitter já oferecem às empresas chats ao vivo, mensagens instantâneas e outras formas de conectar funcionários com seus consumidores. Também nesse sentido, várias organizações disponibilizam fóruns online para integrar o consumidor com os sistemas e processos de desenvolvimento de produtos novos (NAMBISAN; NAMBISAN, 2008).

Dessa maneira, percebe-se que o relacionamento entre empresa e consumidor está cada vez mais em evidência, sendo necessário repensar a forma que as organizações atuam nesse sentido. A seguir será discutido o papel das redes sociais em instituições de ensino.

\subsection{Redes Sociais e Instituições de Ensino}

O mundo aderiu de vez às redes sociais. Segundo o portal de notícias TERRA*, só o Facebook atingiu em dezembro de 2012 um bilhão de usuários, sendo boa parte destes, composta por estudantes. Esse fato não poderia ser ignorado pelas instituições de ensino, uma vez que grande quantidade das informações jogadas na rede por estes estudantes podem interessar a estas instituições. Grupos de alunos que cursam disciplinas em comum organizam fóruns de discussão sobre o assunto visto na aula anterior, professores utilizam as redes sociais para tirar dúvidas dos alunos e diretores mantêm a comunidade externa atualizada a respeito dos últimos feitos da escola/universidade para com a sociedade. Estas ações fazem com que as redes sociais conquistem o papel cada vez mais importante para as instituições de ensino.

De maneira geral, existem diversas vantagens para o estudante na construção de uma relação entre instituição de ensino e redes sociais: Madge et al. (2009) aponta que o aluno se envolve em conseguir as tarefas de aprendizado passadas pela rede; Pasek; Hargittai (2009) afirmam que o aluno desenvolve uma atitude positiva sobre aprendizado; Hew (2011) complementa que o aluno cria seu próprio caminho de aprendizado, por contar com uma grande variedade de instrumentos, aplicações e fontes de informação; o aluno também tem a oportunidade de se comunicar com o professor fora da classe (SELWIN, 2009). As experiências de estudantes com as redes sociais também trazem contribuições inesperadas. Um estudo feito por Selwin (2009) na Inglaterra comprovou que estudantes usam redes sociais não só para criticar experiências de aprendizado ou trocar informações pertinentes aos cursos, mas também para promover suas faltas de engajamento e incompetências.

\footnotetext{
*Link para a notícia: http://tecnologia.terra.com.br/facebook-atinge-1-bilhao-de-usuarios-ativos- mensais,d678de79 92bda310VgnCLD200000bbcceb0aRCRD.html
} 
O professor também pode se beneficiar do uso das redes sociais, uma vez que isso: aumenta a credibilidade de professores engajados na cultura contemporânea do estudante (KABILAN; AHMAD; ABIDIN, 2010); provém saídas educacionais construtivas em uma variedade de campos (PENPEK; YERMOLAYEVA; CALVERT, 2009); pratica uma pedagogia diferente no melhor interesse para o estudante (HEW, 2011); aceita o estudante como um parceiro de interação (SCHWARTZ, 2009); Dabner (2011) finaliza afirmando que o professor se torna preparado para trabalhar em um ambiente educacional digital, que vive em constante crescimento.

Diante do exposto, nota-se uma tendência das instituições de ensino em considerar as redes sociais como parceiros em seus relacionamentos com alunos, professores e comunidade. $\mathrm{A}$ seguir a metodologia utilizada nesta pesquisa será explicada.

\section{METODOLOGIA}

A metodologia a ser adotada na condução da pesquisa proposta é essencialmente exploratória no sentido de buscar conhecer com maior profundidade o assunto, de modo a torná-lo mais claro e a construir questões importantes para a condução da pesquisa (LONGARAY; BEUREN, 2003; MALHOTRA, 2001). Nesse sentido, primeiramente, se utilizará a pesquisa bibliográfica, a qual permite ao investigador se utilizar de informações necessárias à condução da pesquisa de origem secundária, obtidas de documentos que já foram publicados no meio científico. No caso em tela, a pesquisa tem seu foco na temática do CRM Social em Instituições de Ensino.

Com o intuito de atender aos objetivos propostos pelo presente estudo que compreende a análise do papel das redes sociais no IFRN, se utilizou da Entrevista como técnica de coleta de dados por se destacar como um das técnicas de pesquisa mais difundidas e tida como uma das mais importantes para a pesquisa social. Bêrni et al. (2002) define entrevista como uma conversa iniciada pelo entrevistador a fim de obter dados pertinentes sobre um problema de pesquisa. Para Gil (1999), uma das vantagens da entrevista é o grau de profundidade adquirido com a informação, além de não ser exigida do entrevistado a capacidade de ler e escrever.

Para esse estudo optou-se pelo emprego da Entrevista semiestruturada realizada no Departamento de Comunicação Social e Imprensa do IFRN com a coordenadora do departamento $\left(R_{1}\right)$ e uma estagiária $\left(R_{2}\right)$, por permitir ao emprego de questões direcionadas, entretanto abertas, nas quais o entrevistado pode discorrer livremente sobre o tema em questão (BÊRNI et al, 2002).

Em relação à análise dos resultados, utilizou-se a análise de conteúdo que consiste na análise de textos e documentos, com o objetivo de "compreender criticamente o sentido das comunicações, seu conteúdo manifesto ou latente, as significações explícitas ou ocultas" (Chizzotti, 1991, p. 98). Adotou-se nesse estudo também a definição de Bardin (2004) acerca da análise de conteúdo:

[...] a análise de conteúdo aparece como um conjunto de técnicas de análise das comunicações, que utiliza procedimentos sistemáticos e objetivos de descrição do conteúdo das mensagens (BARDIN, 2004, p.33) 
Para o autor, na apreensão do mundo, sob formas de leituras, subsiste, além da denotação, a conotação. É nesse nível que os signos se intercambiam, se combinam e se depreendem a sua significação.

Bêrni et al.(2002) complementa afirmando que tal técnica de análise se constitui como um instrumento versátil, que permite ao investigador tentar construir um conhecimento analisando o discurso, a disposição e os termos utilizados pelo locutor. Nesse presente estudo, a entrevista foi gravada, transcrita e analisada, extraindo os significados explícitos e implícitos do locutor para a partir dessa análise se compreender o papel das redes sociais na instituição de ensino IFRN.

\section{APRESENTAÇÃO E DISCUSSÃO DOS RESULTADOS}

Por meio da entrevista realizada com servidores do Departamento de Comunicação Social e Imprensa do IFRN, pôde-se chegar aos resultados expostos nessa seção. Foram entrevistadas duas servidoras, nominadas de $R_{1}$ e $R_{2}$, que fazem parte desse departamento e que trabalham diretamente com as mídias sociais da Instituição em questão. Inicialmente, $R_{1}$ e $R_{2}$ foram enfáticas ao afirmar que o IFRN trabalha sempre buscando a aproximação com sua comunidade acadêmica e que as mídias sociais são utilizadas com o intuito de fomentar esse estreitamento, preocupação esta destacada por Payne; Frow (2005) como base para o CRM Social. As principais mídias utilizadas pela Instituição são o Facebook, o Twitter e o Fale conosco, um serviço de atendimento da própria instituição. A partir de dados coletados na página do Twitter no mês de junho do ano de 2015, pode-se identificar o IFRN como a Instituição de ensino técnico que mais seguidores tem no país, com um número um pouco maior que 34.000 seguidores, conforme demonstrado na Tabela 1.

Tabela 01: Seguidores no Twitter por Instituição de Ensino

\begin{tabular}{cc}
\hline Instituição de Ensino & No Seguidores no Twitter \\
\hline IFRN & 34.500 \\
\hline IFSC & 9.337 \\
\hline IFC & 8.737 \\
\hline IFPB & 7.720 \\
\hline IFAL & 2.684 \\
\hline IFAM & 2.757 \\
\hline IFB & 2.225 \\
\hline
\end{tabular}

Fonte: Site www.twiter.com . Acessado em 01/07/2015.

O Facebook mostra-se também bastante acessado pela comunidade, com um número de curtidores já ultrapassando a casa dos 74.000. Os números mostram que o IFRN busca aproximarse do seu público alvo e a comunidade mostra-se interessada em participar do processo de construção de uma Instituição de ensino cada vez melhor, colaborando com ideias e gerando feedback do trabalho realizado pela Instituição.

Em relação ao gerenciamento das mídias sociais por parte dos servidores do departamento, fica claro que não há, de forma direta, pessoas responsáveis pela administração das contas. Em regime de colaboração, os servidores lotados no Departamento de Comunicação e Imprensa, desdobram-se para atender aos anseios e dúvidas advindas da comunidade, mas sem que uma determinada mídia seja incumbida a um servidor. De acordo com $R_{2}$, 
"indiretamente há uma divisão, mas quem está no momento no setor é responsável por responder aos questionamentos que surgem nas diversas mídias utilizadas pelo IFRN."

A partir do exposto, observa-se que as respostas são dadas pelos servidores de forma alinhada ao que preceitua a Instituição, porém sem imputação de responsabilidade a um servidor em específico. Nessa perspectiva, as publicações e respostas aos seguidores e curtidores são atualizadas conforme a demanda, no entanto, sem metas diárias de respostas estabelecidas temporalmente. As perguntas são respondidas na medida do possível e as postagens são mais frequentes quando se tem que postar notícias que necessitam de uma difusão rápida, como: editais, resultados de processos seletivos, etc. Com o advento do Twitter e do Facebook, mídias consideradas de difusões instantâneas, houve uma maior aproximação com a comunidade acadêmica e com a comunidade interessada nos serviços oferecidos pelo IFRN. Os elos foram estreitados e, segundo $R_{1}$

"com a utilização mais frequente do Facebook e Twitter, houve uma redução no fale conosco e quanto mais nós atuamos, mais nós somos solicitados pela comunidade interessada".

É perceptível que os interessados nos serviços da Instituição sentem-se acolhidos quando Ihes é dado mais atenção e rapidez. Quanto mais rápida for a resposta dada a um seguidor, maior será a interação desenvolvida entre os partícipes, o que pode ser visto como natural, já que a demanda por respostas é alargada e os servidores tem outros afazeres que não estes.

Depreende-se ainda que as mídias sociais representam uma dicotomia entre o bônus e o ônus de se empregá-las em um ambiente institucional. De acordo com $\mathrm{R}_{1}$ :

"As mídias sociais podem ser consideradas uma benção ou uma maldição. Benção pelo o que já foi comentado e maldição pela insistência, pressão e cobranças estabelecidas ao nosso setor em períodos de processos seletivos, tais como os exames de seleção, PROITEC ou movimentos grevistas".

Essa revelação demonstra que as mídias sociais assumem um papel de suma importância na otimização da disseminação das informações necessárias ao público interessado, como observado por Greenberg (2010). Por outro lado, essas mídias podem trazer consigo altas demandas em períodos específicos ao setor competente, como o setor de Comunicação Social e Imprensa, o que pode dificultar o trabalho rotineiro nessas épocas.

No que tange ao tipo de mídia social mais utilizada, o Facebook se destaca diante do Twitter e o Fale Conosco, sugerindo que a visibilidade dessa mídia social favoreça a esse resultado, bem como a limitação de caracteres do Twitter que inibe o participante de descrever livremente determinado comentário. Quanto ao Fale Conosco, considerada uma mídia social consolidada nas organizações, a utilização é menos presente, uma vez que possui um caráter menos instantâneo que as demais.

Constata-se, também, que a instituição de ensino, foco da pesquisa, reconhece a relevância do papel das mídias sociais na otimização da difusão das informações aos servidores, alunos e comunidade em geral, o que possibilitou a criação de novas facilidades de comunicação entre esses entes, sendo esse resultado corroborado por Verhoef; Lemon (2012). Vale ressaltar 
que a utilização dessas redes sociais são vistas pelo pesquisado de maneiras diferentes para determinado grupo de público, conforme citação a seguir:

"Os servidores só utilizam em casos específicos, como greves. O maior uso é por parte dos alunos e comunidade interessada".

Dessa maneira, pode-se observar que os servidores, docentes e técnicos-administrativos da Instituição de Ensino não utilizam rotineiramente as mídias sociais pra estreitar o relacionamento com seu ambiente de trabalho, exceto em períodos de interesses específicos do grupo. Por outro lado, alunos e comunidade em geral interessada adotam o Facebook, Twitter e o fale conosco no dia-a-dia.

Outro aspecto relevante que foi observado é a não integração entre as mídias sociais da Reitoria da Instituição de Ensino, considerada oficial, e as desenvolvidas pelos outros dezesseis campi da Instituição, o que demanda um olhar cuidadoso da instituição. De acordo com os pesquisados:

"Não basta apenas abrir as contas, mas deve-se alimentar constantemente".

Nesse sentido, a criação de contas nas mídias sociais, como Facebook e Twitter, necessitam de gerenciamento permanente por um setor específico de comunicação em cada campus que possa responder instantaneamente e esclarecer dúvidas, em sintonia com as diretrizes definidas pela reitoria, com o intuito de evitar informações desarticuladas e opostas dentro de um mesmo ambiente institucional.

Por se tratar de uma grande instituição de ensino, é comum a existência de contas e perfis não oficiais do IFRN, frequentemente criadas por alunos e líderes estudantis com o intuito de divulgar notícias e material referente à rotina acadêmica. Isso acarreta muitas vezes na divulgação em massa de informações falsas ou não oficiais a respeito do Instituto. Por isso existe a preocupação do setor em informar que o IFRN não responde pelo conteúdo gerado por tais contas.

Além disso, como a internet muitas vezes dá a seus usuários a possibilidade do anonimato, também é possível encontrar comentários ofensivos ou desrespeitosos nas paginas do IFRN. Os respondentes disseram que tentam responder tais ofensas da forma mais cordial e educada possível, e somente em casos de comentários realmente agressivos cogitam apagá-los da página.

Quando finalmente questionada se era possível educar através das mídias sociais, $R_{1}$ respondeu:

\footnotetext{
"Sim, já que o acesso a educação é facilitado em razão da linguagem utilizada. Como é uma linguagem informal, você meio que está conversando com o aluno, de igual pra igual".
}

Percebe-se então uma concordância entre o conteúdo analisado e a fala das referências supracitadas como Selwyn; Schwartz (2009), uma vez que as redes sociais contribuem para a educação por aproximarem e facilitarem a comunicação entre os alunos e as instituições de ensino. A seguir serão abordadas as contribuições que a pesquisa possibilitou formular. 


\section{CONCLUSÕES}

Esse trabalho buscou compreender o papel que o CRM social exerce em uma Instituição de Ensino, especificamente o Instituto Federal de Educação, Ciência e Tecnologia do Rio Grande do Norte. De acordo com os resultados alcançados nesse estudo, pôde-se chegar à conclusão que as mídias sociais desempenham um papel de relevância na disseminação instantânea das informações e na aproximação do relacionamento entre os alunos e comunidade em geral interessada.

Nesse sentido, observa-se que a busca por informações rápidas e precisas sobre um interesse específico nas principais mídias sociais, exigiu que a Instituição de Ensino se adequasse a essa nova realidade da era da informação, por meio não apenas da criação de contas no Facebook ou Twitter, mas também da inclusão de um ambiente setorial que se preocupe e atenda prontamente as demandas surgidas nessas mídias. Entretanto observou-se que a presença do CRM Social na Instituição dá-se de forma intuitiva, uma vez que não há uma gestão efetiva de relacionamento entre o IFRN e a comunidade interessada.

É possível que essa nova exigência requeira uma articulação e integração maior entre as mídias sociais criadas em cada campus do Instituto e a Reitoria, com o objetivo que informações contraditórias possam ser evitadas. A atuação dos servidores nas mídias sociais é outro aspecto importante que pode ser favorecido por essa integração entre os diversos campi, visto que, atualmente, muitos participam de forma isolada e não articulada com os outros campi com os quais não é o ambiente de lotação do servidor.

Diante desse contexto, a pretensão desse estudo foi contribuir para um melhor entendimento das mídias sociais em uma Instituição de Ensino que possibilite aos pesquisadores buscarem na inovação do conhecimento, a forma capaz de revolucionar e modificar paradigmas estabelecidos na área do CRM Social em um ambiente educacional.

Reconhece-se, finalmente, que muitas questões ainda necessitam de estudos mais aprofundados, como as possíveis implicações no impacto que essas mídias sociais provocam no estreitamento do relacionamento entre servidores, alunos e comunidade em geral interessada. Portanto, se faz necessário um novo olhar, capaz de repensar na forma como as instituições de ensino atuam na aproximação das suas partes interessadas.

\section{REFERÊNCIAS}

1. BARDIN, Laurence. Análise de conteúdo. 3a. Lisboa: Edições, v. 70, 2004.

2. BÊRNI, Duílio de Ávila et al. Técnicas de pesquisa em economia. São Paulo: Saraiva, 2002.

3. CHIZZOTTI, Antonio. Pesquisa em ciências humanas e sociais. Cortez, 1991.

4. DABNER, Nicki. 'Breaking Ground'in the use of social media: A case study of a university earthquake response to inform educational design with Facebook. The Internet and Higher Education, v. 15, n. 1, p. 69-78, 2012.

5. GIL, Antonio Carlos. Como elaborar projetos de pesquisa. São Paulo, v. 5, 2002.

6. GORRY, G. Anthony; WESTBROOK, Robert A. Once more, with feeling: Empathy and technology in customer care. Business Horizons, v. 54, n. 2, p. 125-134, 2011. 
7. GREENBERG, Paul. CRM at the speed of light: social CRM 2.0 Strategies, tools, and techniques for engaging your customers, 2009.

8. HEIDEMANN, Julia; KLIER, Mathias; PROBST, Florian. Online social networks: A survey of a global phenomenon. Computer Networks, v. 56, n. 18, p. 3866-3878, 2012.

9. HEW, Khe Foon. Students' and teachers' use of Facebook. Computers in Human Behavior, v. 27, n. 2, p. 662-676, 2011.

10. HOLZNER, Steven. Facebook marketing: leverage social media to grow your business. Pearson Education, 2008.

11. KABILAN, Muhammad Kamarul; AHMAD, Norlida; ABIDIN, Mohamad Jafre Zainol. Facebook: An online environment for learning of English in institutions of higher education?. The Internet and Higher Education, v. 13, n. 4, p. 179-187, 2010.

12. KOTLER, Philip. Administração de marketing: análise, planejamento, implementação e controle. Atlas, 1994.

13. LONGARAY, André Andrade; BEUREN, Ilse Maria. Como elaborar trabalhos monográficos em contabilidade: teoria e prática. São Paulo: Atlas, 2003.

14. MADGE, Clare et al. Facebook, social integration and informal learning at university:'It is more for socialising and talking to friends about work than for actually doing work'. Learning, Media and Technology, v. 34, n. 2, p. 141-155, 2009.

15. MALHOTRA, Naresh K. Pesquisa de marketing: uma orientação aplicada. Bookman, 2012.

16. MORGAN, J.; CHAN, C.; LIEBERMAN, M. Guide to understanding social CRM. Chess Media Group, 2010.

17. NAMBISAN, Satish; NAMBISAN, Priya. How to Profit From a Better Virtual Customer Environment. MIT Sloan management review, v. 49, n. 3, p. 53-61, 2008.

18. PASEK, Josh et al. Facebook and academic performance: Reconciling a media sensation with data. First Monday, v. 14, n. 5, 2009.

19. PAYNE, Adrian; FROW, Pennie. A strategic framework for customer relationship management. Journal of marketing, v. 69, n. 4, p. 167-176, 2005.

20. PEMPEK, Tiffany A.; YERMOLAYEVA, Yevdokiya A.; CALVERT, Sandra L. College students' social networking experiences on Facebook. Journal of Applied Developmental Psychology, v. 30, n. 3, p. 227-238, 2009.

21. SCHONFELD, Erick. Forrester forecast: Online retail sales will grow to $\$ 250$ billion by 2014. Retrieved May, v. 13, p. 2011, 2010.

22. SELWYN, Neil. Faceworking: exploring students' education-related use of Facebook. Learning, Media and Technology, v. 34, n. 2, p. 157-174, 2009.

23. SCHWARTZ, Harriet L. Facebook: The new classroom commons?.Chronicle of Higher Education, v. 56, n. 6, p. B12-B13, 2009.

24. VERHOEF, Peter C.; LEMON, Katherine N. Successful customer value management: Key lessons and emerging trends. European Management Journal, v. 31, n. 1, p. 1-15, 2013. 